\title{
The Construction Site Management of Concrete Prefabricated Buildings by ISM-ANP Network Structure Model and BIM under Big Data Text Mining
}

\author{
Guiming $\mathrm{Xu}^{*}$ \\ Changzhou Vocational Institute of Engineering, Architectural Engineering Institute, Wujin District, \\ Changzhou City 213164 (China)
}

Received 15 June 2020 | Accepted 28 October 2020 | Published 25 November 2020

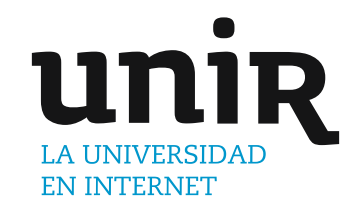

KEYWORDS

Analytic Network Process (ANP), Big Data Text Mining, Building Information Model (BIM), Construction Management, Interpretative Structural Model (ISM).

In the construction industry, prefabricated buildings have developed rapidly in recent years due to their various excellent properties. To expand the application of big data text mining and Building Information Model (BIM) in prefabricated building construction, with concrete as a form of expression, the construction management of concrete prefabricated buildings is discussed. Based on the Interpretative Structural Model (ISM) and Analytic Network Process (ANP), the importance of the safety factors on the construction sites of concrete prefabricated buildings are assessed. Based on BIM, an optimized construction management platform for concrete prefabricated buildings is built, whose realization effects are characterized. The results show that prefabricated buildings have developed rapidly from 2017 to 2019. Compared with traditional buildings, they can significantly reduce the waste of resources and energy, and the savings of water resource utilization can reach $80 \%$. Among the various safety impact elements, construction management has the greatest impact on construction safety, and the corresponding weight value is 0.3653 . The corresponding weight of construction personnel is 0.2835 , the corresponding weight of construction objects is 0.1629 , the corresponding weight of construction technology is 0.1436 , and the corresponding weight of construction environment is 0.0448 . This building construction management platform is able to control the construction progress in real-time and avoid the occurrence of construction safety accidents. The final layout of the construction site shows a good effect, and the deviation between the actual construction schedule and the expected construction schedule is small, which is of great significance for the smooth development of concrete prefabricated buildings. This is a catalyst for the future development of concrete prefabricated buildings and the application of big data technology.

DOI: $10.9781 /$ ijimai.2020.11.013

\section{INTRODUCTION}

$\mathrm{T}$ HE traditional construction industry mainly uses the way of on-site pouring construction. Such constructions require a lot of manpower costs. Meanwhile, during the process of construction, construction wastes, environmental pollutions, and other problems will be produced inevitably [1], [2], while prefabricated buildings have solved these problems perfectly [3]. The so-called "prefabricated buildings" specifically refer to the prefabricated components at the factory or project construction site. With the aid of some connection paths, the scattered components are finally connected as an integrity, which is a means for building construction. Fewer consumables, fast construction, and low strength are the unique properties of prefabricated buildings [4]. Since their invention, the forms of prefabricated buildings have evolved from wood and light steel in the early times and concrete structures in current times. For prefabricated buildings, the completion of the construction goals is achieved

* Corresponding author.

E-mail address: 8000000295@czie.edu.cn through industrialization [5]. Due to the excellent characteristics of prefabricated buildings, China has provided strong support for the development of this industry. In recent years, concrete prefabricated buildings have developed rapidly due to their ease of installation, high efficiency, and the ability to achieve mass production.

Compared with traditional building construction, the proportion of construction personnel required for concrete prefabricated buildings is greatly reduced. Most of the components are prefabricated in the workshop and have a high degree of mechanization; the workload of the entire construction process is reduced; there are higher requirements for the planning of the construction site; at the same time, there are also higher requirements for the details, such as the accuracy of the prefabricated components; moreover, the entire construction process has a higher difficulty compared with the traditional construction [6]; therefore, it has become the main development direction for the transformation and upgrading of traditional buildings. But at the same time, the construction process and the production of prefabricated parts require precise technical support. This building model puts forward more stringent requirements for safety management. Therefore, the safety management of prefabricated building construction must be 
paid attention to. Traditional management methods are more limited in the treatment of accidental hazards. It is currently difficult to meet the management requirements of prefabricated buildings. The rise of big data text mining and Building Information Modeling (BIM) technology provides a good direction for solving this problem. However, the effect of BIM technology in the application process is not very satisfactory. Concrete prefabricated buildings have developed rapidly in recent years. This construction model can effectively reduce the risk of accidents. At the same time, the mechanized construction method has brought convenience to construction management. However, the actual scenarios require the cooperation of multiple people and multiple devices, as well as higher requirements on construction techniques. On the contrary, it can easily lead to safety accidents. Therefore, in the construction process of concrete prefabricated buildings, it is very important to study and discuss the safety management.

Therefore, to apply big data technology to expand the development of concrete prefabricated buildings in the construction industry and achieve effective management and regulation of construction sites, the Interpretative Structural Model (ISM) and Analytic Network Process (ANP) are combined. On this basis, BIM technology is introduced to build a construction management platform for concrete prefabricated buildings. It is hoped to provide some data references for the combination of modern analysis technologies and prefabricated buildings.

\section{LiterATURE REVIEW}

\section{A. Research Progress of Prefabricated Buildings}

At present, scholars from various countries have explored the prefabricated buildings. Aiming at the limitations of prefabricated buildings, Zhao et al. realized the real-time collection and analysis of component information through the combination of Radio Frequency Identification (RFID) and Building Information Model (BIM) technologies [7]. Hwang et al. discussed the important factors affecting the volume structure of prefabricated components in prefabricated buildings and proposed a feasible strategy through the application of BIM [8]. From the perspective of technology promotion and green production, $\mathrm{Wu}$ et al. analyzed the key factors affecting prefabricated buildings by taking the Index of Relative Importance (IRI) as an evaluation indicator; they found that the technology lock-in, incentive policies, and standardization are the important influencing factors [9]. Shi et al. proposed a bolt end-plate connection method and a new construction method, tested the seismic performance of the new prefabricated steel frame based on prefabricated buildings, and found that the proposed method could make the test piece have the good horizontal bearing capacity and elongation performance [10]. Tan et al. explored the obstacles in the application of BIM technology in prefabricated buildings. Finally, by introducing the Interpretative Structural Model (ISM), a corresponding strategy was developed, which provided technical and management solutions for the application of BIM in prefabricated buildings [11].

\section{B. Research Progress of Concrete Prefabricated Buildings}

Thanks to the excellent performance of concrete, the concrete prefabricated buildings have developed rapidly in recent years. Sebaibi and Boutouil used the ground blast furnace slag and ultra-fine silicate cement to improve the energy efficiency of the concrete prefabricated building construction by eliminating heat treatment and reducing the environmental impact of concrete [12]. Tsangouri et al. evaluated the design feasibility and structural integrity of prefabricated building construction components, including concrete cantilever slab bearing steel, through incremental bending tests, which provide test and data support for the development of concrete prefabricated building construction [13]. Ren et al. used a batch of concrete specimens as samples to study the effect of passenger and freight trains with different wheel weights and different speeds on the mechanical properties of prefabricated concrete [14].

In summary, there are many discussions on the application of BIM technology in prefabricated buildings. However, at the same time, there are limitations in the application of BIM technology in prefabricated buildings, while explorations that combine BIM technology with ISM are rare. Among the discussions on concrete prefabricated buildings, those on construction site management are few.

\section{METHOD}

\section{A. A Brief Introduction to Concrete Prefabricated Buildings}

The construction of concrete prefabricated buildings requires coordination of various factors to ensure its smooth progress. For the management of construction site of concrete prefabricated buildings, the construction schedule, construction quality, construction safety, and construction costs should be considered as the management and control objectives for the construction site management of concrete prefabricated buildings. Here, a construction site management platform is built by considering the above factors that affect the construction process. Examples of prefabricated components used in the construction of concrete prefabricated buildings are shown in Fig. 1. For prefabricated buildings, from 2017 to 2019, in the three major types of areas for the development of prefabricated buildings: key areas, active promotion areas, and encouraging areas, the data on the new construction area of prefabricated buildings and the differences between prefabricated and traditional buildings are analyzed.
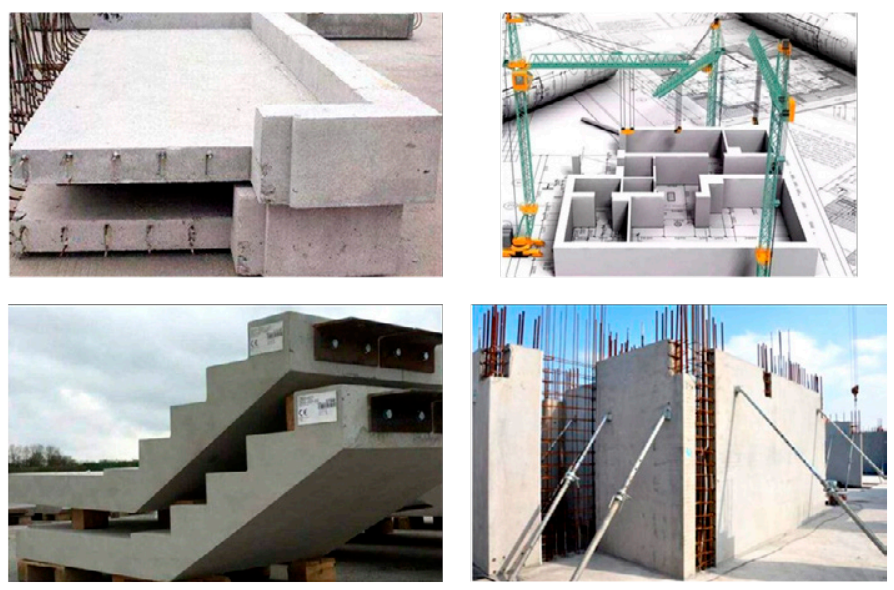

Fig. 1. Examples of prefabricated components used in the construction of concrete prefabricated buildings.

\section{B. Construction Safety Factors Based on ISM-ANP Network Structure Model}

ISM is able to decompose complex systems, thereby analyzing the relations among various constituent elements of each subsystem obtained by the decomposition. The relations among the objects to be analyzed are expressed by directed graph and matrix theory; at present, ISM has been widely used in solving complex economic problems [15], [16]. Directed connection graph, adjacency matrix, and accessibility matrix are the three major elements that constitute ISM [17]. In the adjacency matrix, the system is defined as:

$$
S=\left(S_{1}, S_{2}, \cdots, S_{n}\right)
$$

Where: $n$ represents the number of elements in the system, $S_{1}$ represents the first component in the system, the rest may be deduced by analogy. 
In further, the adjacency matrix is defined as:

$$
\begin{aligned}
A & =\left(\mathrm{a}_{i j}\right)_{n \times n} \\
\mathrm{a}_{i j} & =\left\{\begin{array}{l}
1 \\
0
\end{array}\right\}
\end{aligned}
$$

Where: $A$ represents the adjacency matrix, and $\mathrm{a}_{i j}$ represents the vector in the $i$-th row and $j$-th column of the matrix. If $\mathrm{a}_{i j}$ is 1 , element $S_{\mathrm{i}}$ in the system will have an effect on element $S_{j}$; if $\mathrm{a}_{i j}$ is 0 , element $S_{\mathrm{i}}$ in the system has no effect on element $S_{j}$.

The accessibility matrix is defined as:

$$
(A+I) \neq(A+I)^{2} \neq \cdots \neq(A+I)^{k} \neq(A+I)^{k+1}=M
$$

Where: $k$ corresponds to the number of nodes, $A+I$ represents the matrix, and $M$ represents the accessibility matrix.

ANP is obtained by improving the Analytic Hierarchy Process (AHP). In contrast, ANP considers the interaction between factor groups at the same level and the various elements within the factor group. Its specific implementation process mainly includes the construction of structural models, the construction and calculation of the judgment matrix and super matrix [18], [19]. For example, the unweighted super matrix is constructed as:

$$
W_{i c}=\left[\begin{array}{llll}
w_{i 1}^{\left(c_{1}\right)} & w_{i 1}^{\left(c_{2}\right)} & \cdots & w_{i 1}^{\left(c_{n}\right)} \\
w_{i 2}^{\left(c_{1}\right)} & w_{i 2}^{\left(c_{2}\right)} & \cdots & w_{i 2}^{\left(c_{n}\right)} \\
\vdots & \vdots & \vdots & \vdots \\
w_{i n}^{\left(c_{1}\right)} & w_{i n}^{\left(c_{2}\right)} & \cdots & w_{i n}^{\left(c_{n}\right)}
\end{array}\right]
$$

Where: $w_{i 1}^{\left(c_{1}\right)}$ represents the vector of the corresponding position in the unweighted super matrix, and the rest may be deduced by analogy.

The weighted super matrix is defined as:

$$
A=\left[\begin{array}{llll}
a_{11} & a_{12} & \cdots & a_{1 n} \\
a_{21} & a_{22} & \cdots & a_{2 n} \\
\vdots & \vdots & \vdots & \vdots \\
a_{n 1} & a_{n 2} & \cdots & a_{n n}
\end{array}\right]
$$

Where: $a_{11}$ represents the vector located in the $i$-th row and $j$-th column of the weighting matrix, and the rest may be deduced by analogy.

Furthermore, the calculation of the weighted super matrix is defined as:

$$
\bar{W}=\overline{W_{i c}}=a_{i j} W_{i c}(i=1,2, \cdots, n ; c=1,2, \cdots, n)
$$

Where: $\bar{W}$ represents the weighted super matrix, $i$ and $c$ are factors.

Furthermore, when the weighted super matrix satisfies the following equation, the limit super matrix is obtained so that the importance weight of each component is reflected.

$$
W^{\infty}=\lim _{t \rightarrow \infty} W^{t}
$$

The implementation steps of ISM and ANP in the application are shown in Fig. 2. The implementation process of ISM mainly includes the setting of key issues, the selection of influencing factors, the analysis of influencing factors, and the analysis of the correlation between various factors. Among them, the analysis of correlation is the core. This link mainly includes the construction of adjacency and reachability matrix, region hierarchical division, and relationship generation. The realization process of ANP is an analysis of the relationship between system goals, decision criteria, and various factors.

On this basis, ISM is utilized to analyze the correlation of factors affecting the safety of construction sites of concrete prefabricated buildings. ANP is utilized to analyze the importance of factors affecting the safety of construction sites of concrete prefabricated buildings. The analysis of the correlation of construction site management factors of concrete prefabricated buildings based on ISM is shown in Fig. 3.

As shown in Fig. 3, the factors mainly include the construction safety organization, construction safety supervision, construction safety protection, and construction technical disclosure management. These components of the construction site safety management influence each other; only through coordination and cooperation can the safety management of the concrete prefabricated buildings be guaranteed. Therefore, according to the ANP network structure model, based on the correlation analysis of construction safety management, under the big data text mining technology, the construction personnel, construction technology, construction objects, construction environment, and construction management are fully considered. Furthermore, based on the ISM-ANP network structure model, the network structure relations of the construction safety management influencing factors of concrete prefabricated buildings are shown in Fig. 4.

\section{Construction of An Optimized Construction Management Platform Based on BIM}

BIM applies parameterized models to complete the integration of information in relevant projects, and finally, realizes the update and circulation of the entire project cycle. In this process, the application of BIM also provides a platform for collaborative work [20], [21]. Therefore, BIM technology is critical in promoting the development

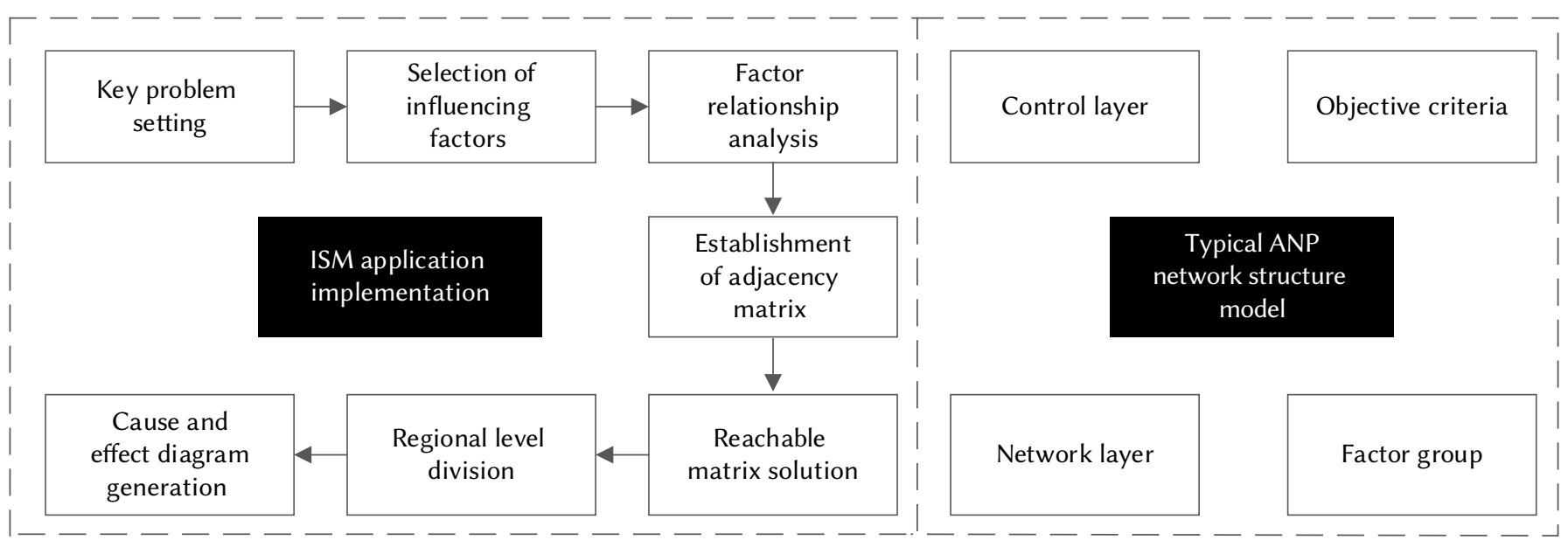

Fig. 2. Implementation of ISM and ANP. 


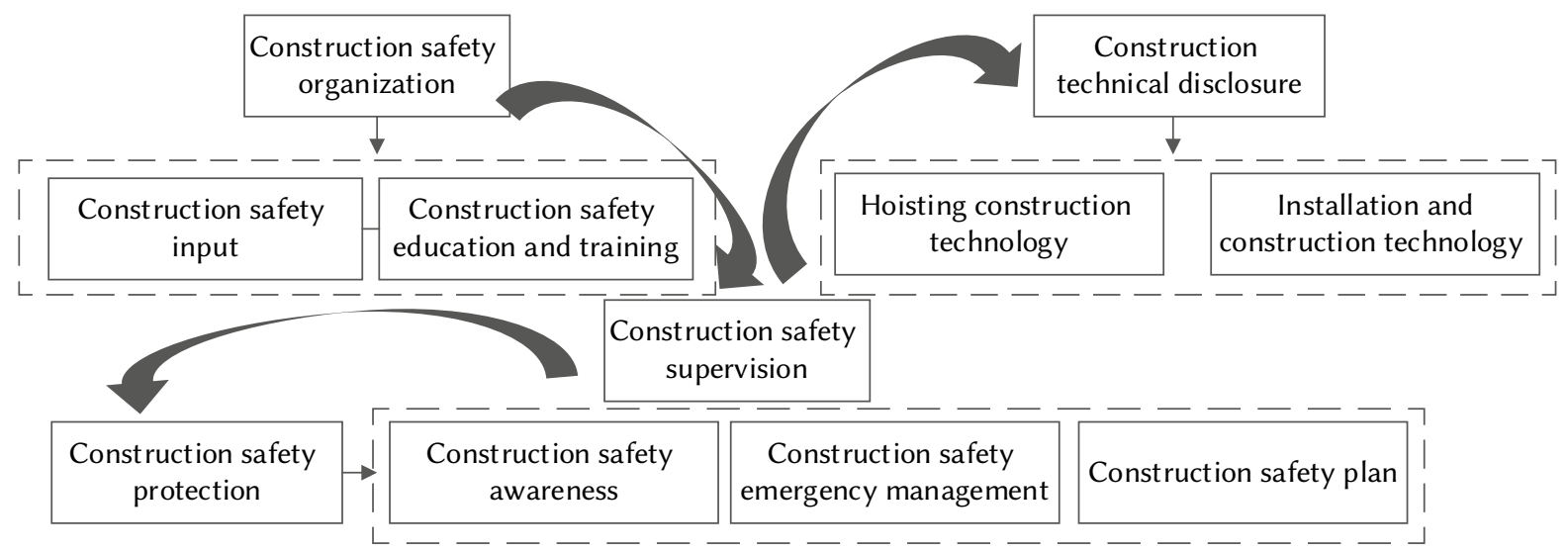

Fig. 3. Correlation between management factors of the construction site.

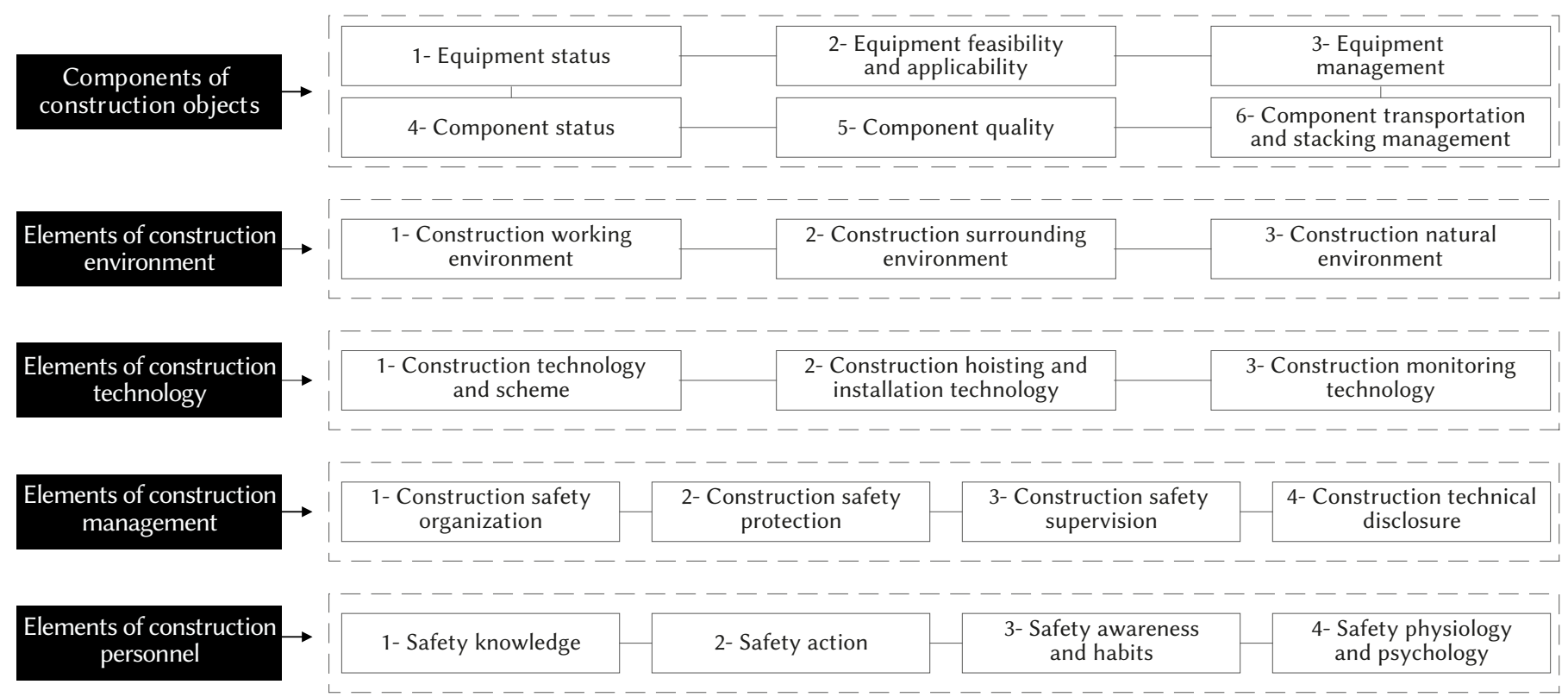

Fig. 4. Network structure relations of construction safety management influencing factors of concrete prefabricated buildings.

\section{Construction schedule management}

\begin{tabular}{|c|c|c|c|}
\hline $\begin{array}{l}\text { Collection of information related } \\
\text { to construction progress }\end{array}$ & \multicolumn{2}{|c|}{$\begin{array}{c}\text { Preparation of } \\
\text { construction schedule }\end{array}$} & $\begin{array}{l}\text { Dev } \\
\text { cons }\end{array}$ \\
\hline & $\begin{array}{c}\text { Adjustment of } \\
\text { construction schedule }\end{array}$ & \multicolumn{2}{|c|}{$\begin{array}{l}\text { Construction progress } \\
\text { related documents }\end{array}$} \\
\hline
\end{tabular}
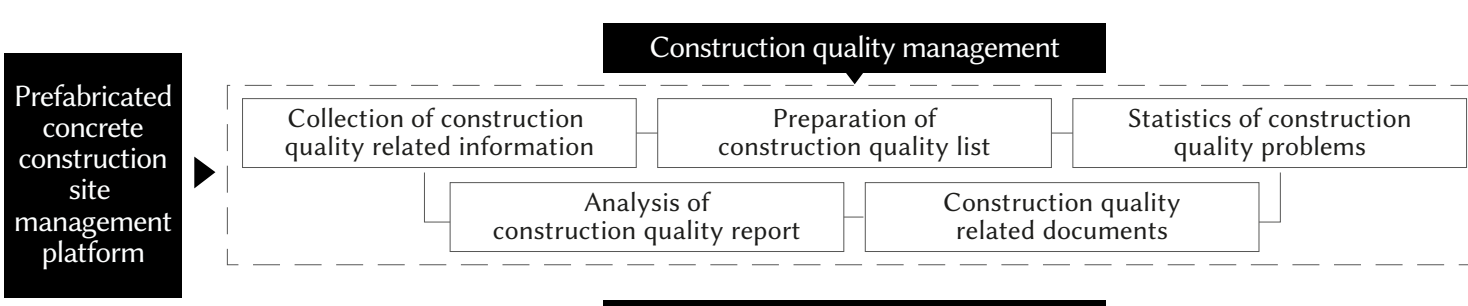

\section{Construction cost management}

\begin{tabular}{|c|c|c|}
\hline $\begin{array}{c}\text { Collection of construction } \\
\text { cost related information }\end{array}$ & $\begin{array}{c}\text { Preparation of } \\
\text { construction cost plan }\end{array}$ \\
\hline $\begin{array}{c}\text { Adjustment of construction } \\
\text { cost plan }\end{array}$ & $\begin{array}{c}\text { Composition of documents } \\
\text { related to construction cost }\end{array}$ \\
\hline
\end{tabular}

Big data text mining

BIM

technology

ISM-ANP network structure model

Fig. 5. Construction site management platform for concrete prefabricated buildings. 
and upgrading of the construction industry. This is also true in the construction of concrete prefabricated buildings. Currently, BIM technology has been well applied in the construction industry. From the perspective of architecture, BIM technology has excellent performances such as visualization, collaboration, simulation, optimization, and drawing [22], [23]. At the same time, incorporating BIM technology into prefabricated buildings has many obvious advantages. From the perspective of the participating contractor, the application of BIM technology facilitates communication during project implementation, and the visualization function of BIM will be well played, which is beneficial to the successful completion of construction projects. From the perspective of the designer, the application of BIM technology can cooperate with professional technicians to identify conflicts, thereby improving efficiency and reducing errors, making control over details more intuitive. From the perspective of the producer, the fine modeling of BIM technology can meet the requirements for prefabricated components, which will significantly improve the pass rate in the production process; thus, the production will be completed accurately. During the production of prefabricated components, the applications of big data-based text mining and Radio Frequency Identification (RFID) chips are also very helpful for improving the efficiency of production management. From the perspective of the project construction party, the application of BIM technology can realize the regulation of construction site management, promote the improvement of assembly accuracy and quality, and avoid the occurrence of errors in the construction process. In summary, it is not difficult to find that BIM technology has high applicability in the construction of prefabricated buildings, which is also applicable in the construction site management of concrete prefabricated buildings.

Based on this, the BIM technology is introduced; combined with the ISM-ANP construction site safety management factors of concrete prefabricated buildings, an optimized construction site collaborative management platform for concrete prefabricated buildings is built. Specifically, the idea of big data text mining is introduced. In big data text mining, it mainly focuses on the research of structured data, such as data based on relationship and data warehouse. From the perspective of text mining, its main purpose is to extract effective information from the relevant information pattern recognition and retrieval. In short, hidden knowledge can be found from batch data through text mining. Based on the above analysis, the construction of collaborative management platform of concrete prefabricated buildings by ISM-ANP is discussed, whose core concept is consistent with big data text mining, such as seeking effective information and mining hidden information mechanism. This is the reason why the idea of big data text mining is introduced.

The construction schedule, construction quality, construction costs, construction safety, and other influencing factors are comprehensively considered, as well as the construction design, component production, prefabricated component transportation, and key parties of the construction. The constructed construction site management platform for concrete prefabricated buildings based on big data text mining and BIM technology is shown in Fig. 5.

\section{Results AND Discussion}

\section{A. Development Analysis of Prefabricated Buildings}

The distribution and changes in construction areas of prefabricated buildings during 2017-2019, as well as the difference between prefabricated buildings and traditional buildings in terms of resource and energy utilization, are shown in Fig. 6 (a) and Fig. 6 (b).

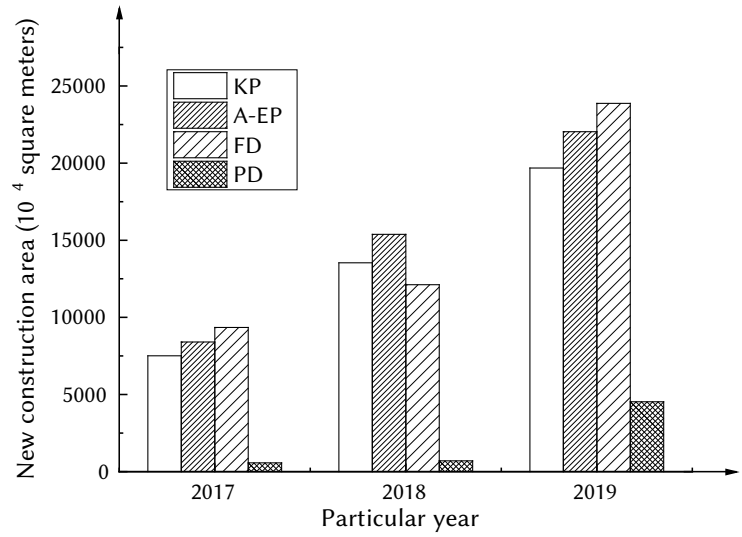

(a)

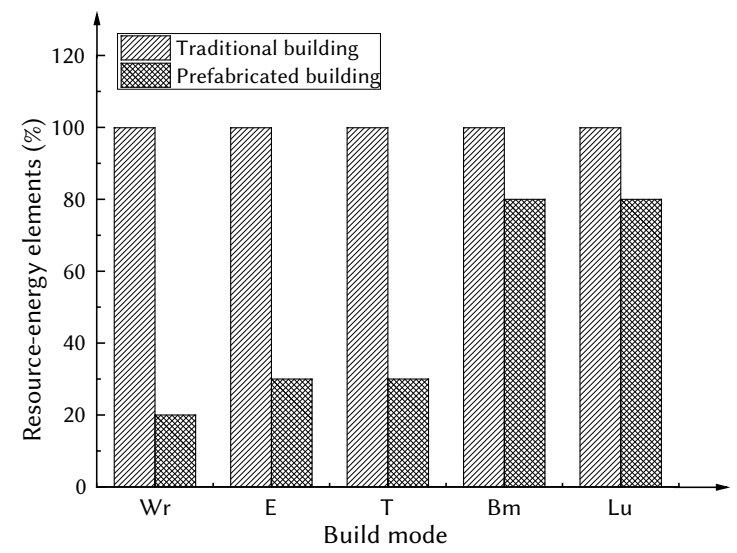

(b)

Fig. 6. Development analysis of prefabricated buildings: (a) Changes in the new construction areas of prefabricated buildings in the past three years, where KP indicates the key promotion area, A-EP indicates the active and encouraging promotion area, FD indicates full decoration, and PD indicates prefabricated decoration; (b) Comparison between traditional buildings and prefabricated buildings, where Wr represents water resources, E represents energy, T represents time, $\mathrm{Bm}$ represents building materials, and Lu represents land use.

As shown in the changes in the new construction areas of prefabricated buildings in the past three years, whether in the key promotion areas, active promotion areas, or encouraging promotion areas of prefabricated buildings, the new construction areas of prefabricated buildings show an annual increase trend. Besides, the area of newly-started prefabricated buildings in the key promotion areas has the most significant growth. In terms of the energy resource utilization, compared with traditional buildings, no matter in the utilization of water resources, energy, construction time, building materials, or construction land use, the energy resource consumption of prefabricated buildings is significantly lower than that of traditional buildings. Especially, in water resource utilization, energy utilization, and construction time, the differences between the two building construction modes are particularly significant. Specifically, the utilization of water resources can be saved by $80 \%$, and energy utilization and construction time can be saved by $70 \%$.

The above analysis shows that the proportion of prefabricated buildings currently used in the construction industry is developing in an increasing direction. At the same time, compared with traditional buildings, prefabricated buildings show many excellent performances in the utilization of resources and energy, which significantly reduce the consumption and waste of resources and energy. In addition, the applications of various modern mechanical methods in the construction process make prefabricated buildings also have significant advantages 
in terms of improving construction efficiency. With the continuous development and deepening of big data mining technology, as well as the implementation of modern mechanical automation construction methods, it is believed that the construction of prefabricated buildings will have greater development and application potentials in the future. In the construction industry, the application of concrete is extremely extensive; thus, the construction of concrete prefabricated buildings will inevitably develop into the mainstream of prefabricated buildings in the future.

\section{B. The Importance Analysis of Construction Safety Factors of Concrete Prefabricated Buildings}

Based on the composition of the network structure of the construction safety management influencing factors of concrete prefabricated buildings, the analysis results of the importance of each construction safety factor are shown in Fig. 7.

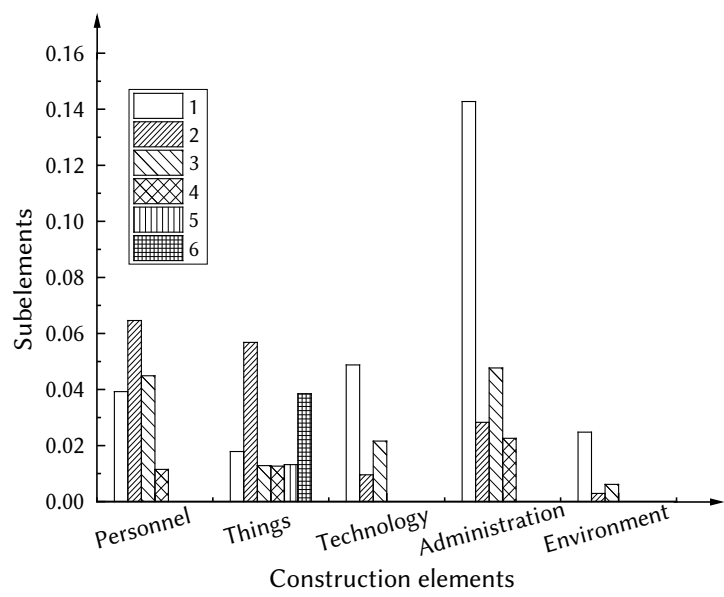

Fig. 7. Analysis results of the importance of factors affecting construction safety.

As shown in Fig. 7, the average weight corresponding to the construction management factor is 0.3653 , which is the most important among all the construction safety influencing factors, followed by the construction personnel factor, whose corresponding average weight value is 0.2835 , the construction objects factor, whose corresponding average weight value is 0.1629 , and finally, the construction technology factor and the construction environment factor, whose corresponding average weight values are 0.1436 and 0.0448 , respectively.

The above analysis shows that, among all the construction safety influencing factors of concrete prefabricated buildings, construction management is the most important one since it reflects the concerns from senior management personnel and persons responsible for construction safety, as well as the amount of human and material resources invested in the construction process, safety management implementation measures, and organizational arrangements. If insufficient attention is paid to this link, incorrect decision-making will occur. No matter what advanced construction techniques and methods are used and how professional the technical personnel is, the construction works will be vain. However, from another perspective, the smooth development and realization of the entire construction process of concrete prefabricated buildings require coordination and cooperation between various links. Any problem in any link will have some negative impacts on the final result. Therefore, it is necessary to deal with the coordinated development between construction management, personnel, objects used, and environment. At the construction safety level, management is the priority. For the overall construction process, the site management of the construction of concrete prefabricated buildings is also very critical. This also lays a good foundation for the application of collaborative BIM technology in the construction of concrete prefabricated buildings.

\section{Realization Effect of the Optimized Construction Management Platform of Concrete Prefabricated Buildings}

Based on the optimized construction management platform of concrete prefabricated buildings, the results of the comparison between the actual construction progress and the expected construction progress, and the changes in the flow of people at safety exits in a certain area at the construction safety level, are shown in Fig. 8 (a) and Fig. 8 (b).

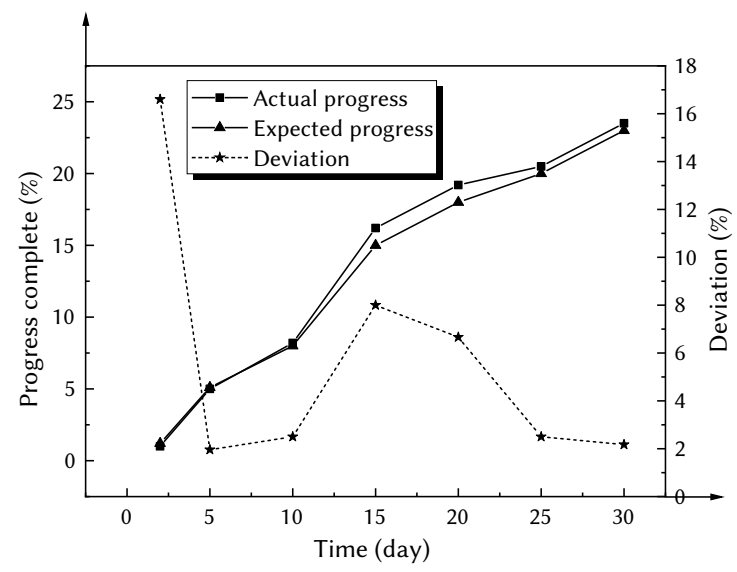

(a)

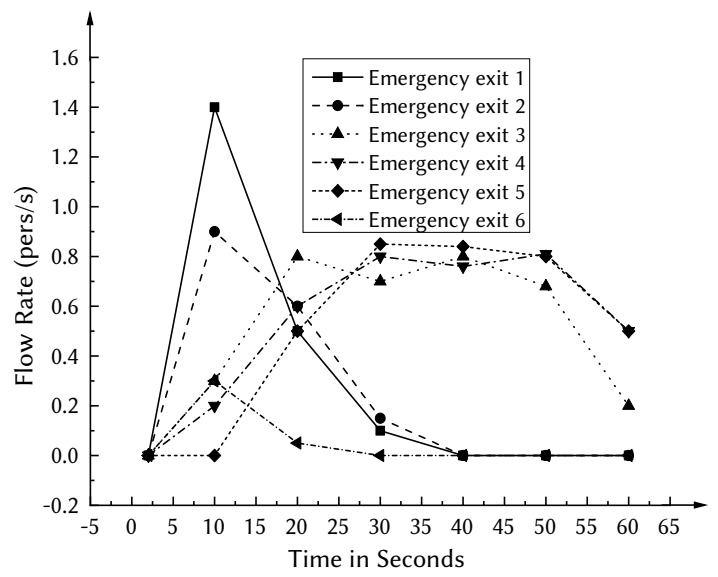

(b)

Fig. 8. Implementation of an optimized construction management platform for concrete prefabricated buildings: (a) Comparison of actual and expected construction progress; (b) Changes in the number of people at safe exits.

By analyzing the data changes in Fig. 8, it is found that the optimized construction management platform for concrete prefabricated buildings is more accurate in controlling the construction progress. Meanwhile, the deviation between the actual construction progress and the expected construction progress is not very huge. The construction management platform based on BIM technology has the characteristics of visualization; thus, it is able to display the construction progress in real-time; in turn, it analyzes the deviation between the actual construction schedule and the expected construction schedule. By finding the deviation, the construction schedule is adjusted. Through the control of construction safety management elements of concrete prefabricated buildings based on the ISM-ANP network structure model, it is possible to effectively control the persons entering and exiting the safety exits of the construction site to avoid congestion and safety accidents. 
By analyzing the data changes in Fig. 8, it is found that the optimized construction management platform for concrete prefabricated buildings is more accurate in controlling the construction progress. Meanwhile, the deviation between the actual construction progress and the expected construction progress is not very huge. The construction management platform based on BIM technology has the characteristics of visualization; thus, it is able to display the construction progress in real-time; in turn, it analyzes the deviation between the actual construction schedule and the expected construction schedule. By finding the deviation, the construction schedule is adjusted. This is similar to the effective information acquisition emphasized in the big data text mining idea, which shows that the construction of collaborative management platform and big data text mining has achieved the preliminary integration. Through the control of construction safety management elements of concrete prefabricated buildings based on the ISM-ANP network structure model, it is possible to effectively control the persons entering and exiting the safety exits of the construction site to avoid congestion and safety accidents.

Based on the optimized construction management platform of concrete prefabricated buildings, the realization effects of the prefabricated buildings in terms of transportation, prefabricated component production, and the construction site management of concrete prefabricated buildings are shown in Fig. 9.
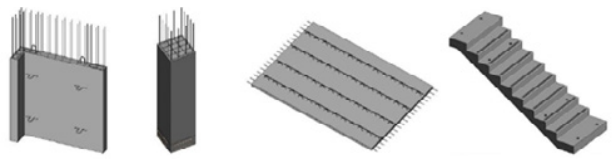

Prefabricated component

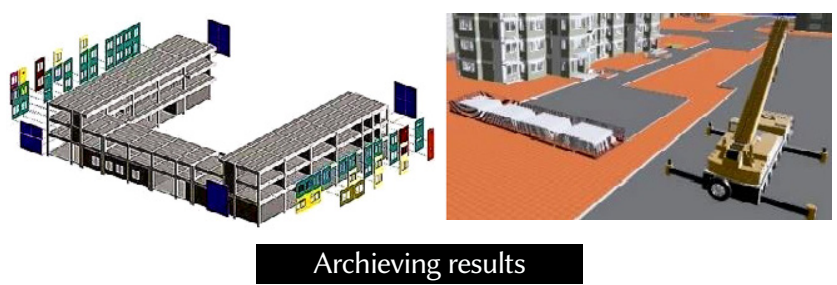

Fig. 9. Actual implementation results of construction site management of concrete prefabricated buildings.

By using the ISM-ANP network structure model to evaluate the safety elements of concrete prefabricated buildings, in addition to the construction of an optimized management platform for construction sites of prefabricated buildings based on big data text mining and BIM technology, the construction site management of the prefabricated buildings shows excellent results. Based on the BIM technology and the ISM-ANP network structure model, the participating organizations or personnel can coordinate to arrange the layout of the construction site, thereby reducing the major changes during the construction process. The practical application value and specific application of BIM technology in prefabricated buildings are briefly described from the aspects of design, manufacturing, and installation. Regarding the application effect of BIM technology in the construction of concrete prefabricated buildings, the conclusions obtained here are basically the same as the conclusions drawn by Liao [24]. However, due to the introduction of big data mining technology, the implementation of construction site management here not only optimizes the quality of concrete prefabricated buildings but also combines the advantages of modern data technology, which has stronger autonomous operation and controllability. Meantime, it can capture the effective information in real time, further optimize the management quality, and improve the efficiency.
V. Conclusion

The innovative introduction of big data text mining and BIM technologies has helped in building the construction site management platform for concrete prefabricated buildings. It is found that construction management is the most critical influencing factor in site safety. Big data mining and BIM technologies have great application potential in site management for the construction of concrete prefabricated buildings. The constructed management platform has achieved good results. However, in the construction of the ISM-APN network structure model, the sub-elements under each component have not been analyzed in detail. At the same time, due to the influence of multiple factors such as experimental conditions, the construction personnel, construction technology, construction objects, construction environment, and other influencing factors that affect the management of the construction site are not analyzed. In addition, the application scope of BIM technology in prefabricated buildings is not very comprehensive. In the future, the sub-factors of each influencing factor will be discussed, and more in-depth analysis and discussion on the application of BIM technology will be conducted from the perspectives of site equipment management and safety protection management.

\section{REFERENCES}

[1] T. Wang, G. Q. Zhou, D. Y. Chao, and L. J. Yin, "Influence of hydration heat on stochastic thermal regime of frozen soil foundation considering spatial variability of thermal parameters," Applied Thermal Engineering, vol. 142, pp. 1-9, 2018, doi: 10.1016/j.applthermaleng.2018.06.069.

[2] Y. W. Lee, J. Seo, S. Kim, Y. J. Kang, and D. Won, "Cyclic Lateral Performance Evaluation of Precast Double-Skinned Composite Tubular Columns," International fournal of Steel Structures, vol. 18, no. 1, pp. 97113, 2018, doi: 10.1007/s13296-018-0308-3.

[3] G. Tumminia, F. Guarino, S. Longo, M. Ferraro, M. Cellura, and V. Antonucci, "Life cycle energy performances and environmental impacts of a prefabricated building module," Renewable and Sustainable Energy Reviews, vol. 92, pp. 272-283, 2018, doi: 10.1016/j.rser.2018.04.059.

[4] Q. Shen, Y. Yu, J. Hou, Q. Wang, L. Zhang, and X. Meng, "The Testing Research on Prefabricated Building Indoor Thermal Environment of Earthquake Disaster Region," Procedia Engineering, vol. 205, pp. 453-460, 2017, doi: 10.1016/j.proeng.2017.10.406.

[5] R. S. Xin, H. L. An, S. Ren, J. T. Yao, and J. Pan, "Behaviors of Continuous Cooling Transformation and Microstructure Evolution of a High Strength Weathering Prefabricated Building Steel," Solid State Phenomena, vol. 279, pp. 21-25, 2018, doi: 10.4028/www.scientific.net/SSP.279.21.

[6] Z. Dong, G. Wu, X. L. Zhao, H. Zhu, and X. Shao, "Behaviors of hybrid beams composed of seawater sea-sand concrete (SWSSC) and a prefabricated UHPC shell reinforced with FRP bars," Construction and Building Materials, vol. 213, no. 20, pp. 32-42, 2019, doi: 10.1016/j. conbuildmat.2019.04.059.

[7] L. Zhao, Z. Liu, and J. Mbachu, "Development of Intelligent Prefabs Using IoT Technology to Improve the Performance of Prefabricated Construction Projects," Sensors, vol. 19, no. 19, pp. 4131, 2019, doi: 10.3390/s19194131.

[8] B. G. Hwang, M. Shan, and K. Y. Looi, "Key constraints and mitigation strategies for prefabricated prefinished volumetric construction," fournal of Cleaner Production, vol. 183, no. 10, pp. 183-193, 2018, doi: 10.1016/j. jclepro.2018.02.136.

[9] G. Wu, R. Yang, L. Li, X. Bi, B. Liu, and S. Li, "Factors influencing the application of prefabricated construction in China: From perspectives of technology promotion and cleaner production," fournal of Cleaner Production, vol. 219, no. 10, pp. 753-762, 2019, doi: 10.1016/j. jclepro.2019.02.110.

[10] G. Shi, H. Yin, and F. Hu, "Experimental study on seismic behavior of full-scale fully prefabricated steel frame: Global response and composite action," Engineering Structures, vol. 169, no. 15, pp. 256-275, 2018, doi: 10.1016/j.engstruct.2018.05.052

[11] T. Tan, K. Chen, F. Xue, and W. Lu, "Barriers to Building Information 
Modeling (BIM) implementation in China's prefabricated construction: An interpretive structural modeling (ISM) approach," fournal of Cleaner Production, vol. 219, no. 10, pp. 949-959, 2019, doi: 10.1016/j. jclepro.2019.02.141.

[12] N. Sebaibi, and M. Boutouil, "Reducing energy consumption of prefabricated building elements and lowering the environmental impact of concrete," Engineering Structures, vol. 213, pp. 110594, 2020, doi: 10.1016/j.engstruct.2020.110594.

[13] E. Tsangouri, O. Remy, F. Boulpaep, S. Verbruggen, G. Livitsanos, and D. G. Aggelis, "Structural health assessment of prefabricated concrete elements using Acoustic Emission: Towards an optimized damage sensing tool," Construction and Building Materials, vol. 206, no. 10, pp. 261-269, 2019, doi: 10.1016/j.conbuildmat.2019.02.035.

[14] J. Ren, S. Deng, and K. Wei, "Mechanical property deterioration of the prefabricated concrete slab in mixed passenger and freight railway tracks," Construction and Building Materials, vol. 208, no. 30, pp. 622-637, 2019, doi: 10.1016/j.conbuildmat.2019.03.039.

[15] G. Li, D. Huang, C. Sun, and Y. Li, "Developing interpretive structural modeling based on factor analysis for the water-energy-food nexus conundrum," Science of the Total Environment, vol. 651, pp. 309-322, 2019, doi: 10.1016/j.scitotenv.2018.09.188.

[16] Y. Li, B. Sankaranarayanan, D. T. Kumar, and A. Diabat, "Risks assessment in thermal power plants using ISM methodology," Annals of Operations Research, vol. 279, no. 1-2, pp. 89-113, 2019, doi: 10.1007/s10479-018-31217.

[17] S. G. Azevedo, T. Sequeira, M. Santos, and L. Mendes, "Biomass-related sustainability: A review of the literature and interpretive structural modeling," Energy, vol. 171, no. 15, pp. 1107-1125, 2019, doi: 10.1016/j. energy.2019.01.068.

[18] Z. Y. Sun, J. L. Zhou, and L. F. Gan, "Safety assessment in oil drilling work system based on empirical study and Analytic Network Process," Safety Science, vol. 105, pp. 86-97, 2018, doi: 10.1016/j.ssci.2018.02.004.

[19] K. J. Wang, Y. D. Lestari, and V. N. B. Tran, "Location Selection of Hightech Manufacturing Firms by a Fuzzy Analytic Network Process: A Case Study of Taiwan High-tech Industry," International fournal of Fuzzy Systems, vol. 19, no. 5, pp. 1-25, 2017, doi: 10.1007/s40815-016-0264-z.

[20] A. Francisco, H. Truong, A. Khosrowpour, J. E. Taylor, and N. Mohammadi, "Occupant perceptions of building information model-based energy visualizations in eco-feedback systems," Applied Energy, vol. 221, pp. 220228, 2018, doi: 10.1016/j.apenergy.2018.03.132.

[21] Z. P. Song, G. L. Shi, J. B. Wang, et al., "Research on management and application of tunnel engineering based on BIM technology," fournal of Civil Engineering and Management, vol. 25, no. 8, pp. 785-797, 2019, doi: 10.3846/jcem.2019.11056.

[22] M. Marzouk, and A. Othman, "Modeling the performance of sustainable sanitation systems using building information modeling," fournal of Cleaner Production, vol. 141, no. 10, pp. 1400-1410, 2017, doi: 10.1016/j. jclepro.2016.09.226.

[23] J. Yuan, X. Li, X. Xiahou, N. Tymvios, Z. Zhou, and Q. Li, "Accident prevention through design (PtD): Integration of building information modeling and PtD knowledge base," Automation in construction, vol. 102, pp. 86-104, 2019, doi: 10.1016/j.autcon.2019.02.015.

[24] Z. Liao, "Application of BIMTechnologyin Design and Construction of Assembled Buildings," Paper Asia, vol. 34, no. 4, pp. 47-50, 2018.

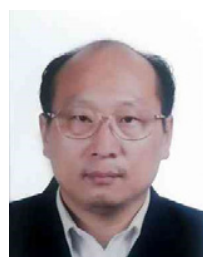

Xu Guiming

Xu Guiming was born in August 1967 in Jiangyan District, Taizhou City, Jiangsu Province, China. In 1989, he obtained a bachelor's degree from Chongqing University, China, and in 2004, he obtained a master's degree in engineering from Hohai University, China. Now, he is a teacher at Changzhou Engineering Vocational and Technical College in China. His research interests include building information modeling , electromechanical engineering installation and computer engineering drawing, etc. 